\title{
A Typology of Alternative Online Political Media in the United Kingdom: A longitudinal content analysis (2015-2018)
}

Alternative online political media (AOPM) have become increasingly prominent elements of the media system in many countries. In response, numerous academic studies have examined the nature of these newer forms of alternative media. In line with this recent scholarship, in this study we carry out a longitudinal and systematic content analysis of nine AOPM websites in the United Kingdom (UK) $(N=3452)$ between 2015 and 2018. Overall, we found a diversity of content, contrasting values and degrees of partisanship, which we develop into a typology of outlets. This includes four overlapping areas: electoral hyperpartisans, cultural partisans, political cycle specialists, and vernacular macro-blogs. We conclude by recommending that scholars need to develop more detailed content analyses in order to better understand online alternative media, their interactions with the wider media system, and the system itself.

In recent years, new forms of 'alternative media’ have become increasingly prominent within the media system in many countries and have had a growing impact on politics and public debate (see Hylton, 2017, Waterson, 2017). Of course, alternative media have long been part of the media (Atton 2002; Harcup 2005) but their newfound prominence has renewed scholarly interest. In the US for example, research has been driven by the emergence of Breitbart News, which was considered important in the election of Donald Trump as US President (Woolf, 2019). In the UK, where many alternative media outlets have emerged, interest has been driven by left-wing outlets such as The Canary, credited with facilitating and supporting the Labour Leadership of Jeremy Corbyn (Conte, 2016). The relative novelty of these outlets has led to recent empirical research focusing on understanding and defining these new forms of alternative media at a more fundamental level.

This study contributes to this growing field of evidence by carrying out a longitudinal (2015-2018) manually-coded, content analysis of online articles $(\mathrm{N}=3452)$ produced by nine outlets in the UK, which has been comparatively underexplored in the recent literature. Using five interpretive variables, we measure the balance of news and comment output, the topicality of their agenda, the level of policy coverage, and their degree of partisanship. In doing so, we follow the aims of other recent studies of alternative media and provide a clearer, fundamental understanding of these outlets, their content, agendas and partisanship. Specifically, we develop a typology of alternative media outlets in the UK by building on the "nonnormative, 
multilevel relational” conceptualisation of alternative media provided by Holt, et al (2019:1). Ultimately, this study brings a comparative, evidence-based understanding of alternative media in the UK into dialogue with the existing international literature.

\section{Outlining the UK context (2015-2018)}

Since 2015, numerous left-wing alternative media outlets, such as Another Angry Voice, Evolve Politics, The Canary, Novara Media, and The Skwawkbox have gained a foothold in the UK's digital media environment (Chakelian, 2017; Waterson, 2017). Similarly, “alt-right” platform Breitbart News, which had gained prominence in the 2016 US Presidential election (see Woolf, 2019), and pro-Brexit outlet Westmonster, launched in 2017 (Jackson, 2017), were seen as growing trend of digital-based, partisan outlets sharing a symbiotic relationship with populist politics (Rae, 2020). The left-wing outlets in particular are seen by media commentators as being closely connected to the Labour Party under Jeremy Corbyn. Moreover, the blog-turnednews-site Guido Fawkes is also associated with the growing supply of alternative content, with its editor Paul Staines referring to The Canary as its “left-wing competition” (Mayhew, 2017). Having emerged in a distinctly different political era (established in 2004), ‘Guido’ represented a type of 'legacy' alternative media site (see Turvill, 2015). Fundamentally, between the period that we examine in this study (2015-2018), numerous alternative outlets were either established and/or enhanced their profile and audience reach.

During this period of rapid organisational growth of these outlets in the UK, as well as their increased consumption among marginal or niche political audiences, their provocative and/or seemingly hyperpartisan content, their tension with or hostility towards mainstream media organisations, a catalytic dependency on platform intermediaries (see Neilsen \& Ganter, 2018) and their associated advertising models were all identified as common elements (see Chakelian, 2017; Conte, 2016; Dolan, 2015; Spence 2016; Waterson, 2017). The Canary, for example, was noted for its transformation from “ $£ 500$ start-up to top-100 UK news website in the space of a year", their growth being driven by Facebook traffic and advertising income (Mayhew, 2016). Meanwhile, Paul Staines described his outlet’s “niche” political content, its reliance on Twitter traffic, and longstanding tensions with "the lobby" (Turvill, 2015). Westmonster, the Arron Banks funded pro-EU outlet, purposefully exploited the large Facebook following of Leave.EU and has been described by its editor Michael Heaver as drawing on Breitbart in its “not politically correct” approach (Jackson, 2017).

While this commentary has identified the emergence and importance of these outlets, only rarely has it understood them together as a broader trend within the media system. This 
study attempts to interpret these outlets through an analysis that collectively identifies their similarities and differences within a proposed typology.

\section{Understanding and interpreting alternative online political media}

\section{Existing Research}

The term 'alternative media' is historical and polysemous (Gibbs \& Hamilton, 2001). For example, the evolution of alternative media can be traced back to $19^{\text {th }}$ century radical newspapers (Hamilton and Atton 2001), the progressive and democratic movements of recent decades (Atton, 2002; Downing, et al, 2001) and the early internet (Couldry \& Curran, 2003).

This study's rationale derives from the collective acknowledgement that in contrast to these earlier eras, a “distinct, digital-first subculture of media” has emerged (Rae, 2020: 2), which can be observed though outlets such as Breitbart, Steigan.no, Westmonster, PI News, and The Canary. However, there is an uncertainty about how to conceptualise these forms of alternative media, with much of the debate related to, and in some ways in conflict with, the historical scholarship of alternative media more broadly (see Holt, et al, 2019; Holt, 2018; Nygaard, 2020 for relevant summaries). As a result, many newer definitions and labels have emerged, including “alternative and partisan news websites” (Newman, et al 2019: 23), "hyperpartisan news” (Rae, 2020), “alternative news media” (Holt, et al 2019) and “alternative online media” (Schulze 2020), as newer studies get to grip with the fundamental aspects of newer forms of alternative media. We use the term 'alternative online political media' (AOPM) to identify the outlets herein. Firstly, by "alternative" we adopt Holt, Figenschou, and Frischlich’s (2019: 3) definition of “a proclaimed and/or (self-) perceived corrective, opposing the overall tendency of public discourse emanating from what is perceived as the dominant mainstream media in a given system”. All the outlets in our UK-based study routinely position themselves as being in some way in opposition to mainstream media. Secondly, "online" denotes that these outlets are "digital-born organisations" (see Nicholls, et al, 2018), relying on the affordances of the internet and digital technologies to access the public sphere (Holt, et al, 2019: 861), including for example, using social media platforms and websites to reach and deliver content to their audiences. By “political media”, we highlight their explicit ideological or agenda-driven editorial positions.

In an attempt to grasp the fundamental nature of newer alternative media, recent studies have conducted cross-national content analysis of alternative media content. Two of the most detailed have been conducted by Heft and colleagues (2019; 2020). In the first, they examined 
70 European and American "alternative right-wing online news sites" and their social media accounts, and identified a "systematic variation” in digital infrastructures providing substantive evidence about the outlets' "different patterns of supply and demand, as well as distinct funding structures, organizational strategies, and thematic tendency” (Heft et al., 2019: 19). In the second study, the researchers systematically analysed the hyperlink networks of 65 sites across six western democracies, and crucially concluded that "legacy news outlets primarily serve as transnationally shared reference points for the alternative news ecologies on the right” (Heft et al., 2020: 15). Analysis of 'fake news' sites conducted by Robertson and Mourão (2020) found that they adopted the discursive features of both mainstream and alternative journalism, leading to an "understanding and definition of fake news sites as hybrid actors producing hyperpartisan news content from alternative perspectives”. Beyond these studies, research has also focussed on right-wing alternative media in a European context (Holt, 2019). For example, Nygaard's (2019) content analysis of right-wing Scandinavian outlets ( $n=90$ articles) explores the stylistic strategies used to present anti-immigration messaging. Figenschou and Ihlebæk’s (2019) content analysis of six right-wing Norwegian outlets ( $\mathrm{n}=600$ articles) produced key findings on how these sites criticise the media and challenge journalistic authority (see also Riebling and Wense, 2019).

In addition to content analyses, studies have also understood newer alternative media through audience studies. A systematic study by Schulze (2020) applied a regression analysis to survey data of alternative media users across European countries and found a polarising and mobilising influence of the content on right-wing audiences. Haller and Holt (2019) examined the use of alternative media sources by users on PEGIDA's German and Austrian Facebook pages, finding that these sources were regularly used to affirm anti-system or anti-immigration views. Noppari, Hiltunen and Ahva (2019) interviewed Finnish users of "populist countermedia" and found that their consumption was driven by scepticism and mistrust of mainstream journalism. In the US, Peacock et al. (2020) surveyed how both Democrats and Republicans ( $n=823$ respondents) consumed 40 different "hyperpartisan news" sites (using a different definition to Rae), and found a positive link between political partisanship and exposure to this content. Interview research by Schwarzenegger (2021), however, found that users of alternative media possessed ambivalent features, thus problematising the homogenous view of alternative media and its users as fundamentally anti-system or populist, thus inviting further, detailed analyses.

Faced with the emergence of digital-based alternative media, many of these studies have taken an axiomatic approach of defining or problematising what we know fundamentally 
about alternative media. In other words, studies have focused on what alternative media are in various national contexts, as reflected in the range of definitions. This study builds on this international literature through a detailed case study of AOPM content in the UK. Accordingly, we contribute to the further understanding of the fundamentals of alternative media by developing a typological framework that might serve as a useful analytical framework hereafter.

\section{Establishing a Typology of Alternative Media in the UK}

To date, empirical research about alternative media in the UK is limited, despite outlets such as The Canary having become well established (Conte 2016). Dodson (2018) has examined the 'recycling' of sources from mainstream media as a routine practice for The Canary, to demonstrate their reliance on other areas of the media system. Key examples of UK findings also include Reuters Digital News Reports research on the reach and consumption of highprofile outlets such as The Canary and Westmonster (see Kalogeropoulos \& Newman, 2018; Newman et al, 2019: 23; Fletcher et al, 2020). A second key contribution is provided by Rae (2020: 2), who argues that UK sites such as Westmonster, Another Angry Voice, The Canary, Evolve Politics, Novara Media and The Skwawkbox should be understood as "hyperpartisan news”, albeit Rae acknowledges this conceptual definition as a "provocation” and "a starting point”.

To assist our fundamental understanding of UK alternative media, we analyse our empirical evidence through the "nonnormative, multilevel relational" model of alternative media (Holt, et al 2019: 1). Specifically, we do so with the aim of creating a conceptual typology that attends to the specifics of the British media system, and in doing so provide a practical conceptual framework to be applied in further study.

Holt et al (2019: 6) conceptualise alternative media in relation to mainstream media, within a respective media system, along five relational levels. The first two operate at a micro level: content producers and the content and style of the content. The two meso levels are publishing routines (such as editorial processes) and organisational features (funding, reach, newsrooms). Finally, at the macro level, outlets are positioned within the wider media system and its function therein.

The key conceptual element is that alternative media are understood in relation to actually existing mainstream journalism, as opposed to abstract conceptualisations of normative journalism. As Deuze (2019: 3) explains, conceptualisations of "non-mainstream” “journalisms" have often been "tamed" or simplified in the service of a normative ideal or 
benchmark of journalism. Foundationally, alternative media have always been an alternative to mainstream media (Harcup, 2005), though as Rauch (2016: 757) explains, in practice, this relationship is always "interdependent, antagonistic, fluid and contingent” as both alternative and mainstream media organisations emerge, evolve, and fade. By understanding the alternative media outlets in our study as “an 'alternative' and 'in regard' to” (Holt et al, 2019: 7) the mainstream, and by thus eschewing a single, normative theorisation of journalism, the "messiness intrinsic to our object of study, only amplified and accelerated by changes in working conditions, information and communication technologies, and business models” (Deuze, 2019: 3) is more visible in the analysis.

This messiness that Deuze calls for, therefore, creates the conceptual space for the typology developed from our empirical evidence. Importantly, it means that similarities and differences can be empirically understood within context, as opposed to normative ideals that may not exist in practice. As Holt (2018:50) has argued, there is a "discrepancy between the dominant theories about alternative media and alternative media as they actually are”, suggesting the need for greater empirical evidence and an inductive theoretical approach, as is provided here. As Schulze (2020: 8) puts it, stable conceptual definitions will remain debatable “in the absence of further content specific analyses”.

Our research questions include:

1) What are their agendas of AOPM outlets, in terms of topics and coverage?

2) How do these outlets cover political parties and to what degree are they partisan?

3) Based on the findings of (1) and (2), what conceptual typology of these outlets can be produced, in the context of the UK's hybrid media system?

\section{Method}

\section{Data and Sample Selection}

The data consists of 3452 online articles produced by nine outlets, within four sampling periods: 5 - 25 October 2015; 9 - 29 October 2016; 30 April - 7 June 2017 (general election); and 8 - 28 October 2018 (see table 1). We included the 2017 general election campaign to examine content within an important democratic period, which we could then compare with the other sampling periods. October was selected because it approximates a 'politics as normal' period, as opposed to the summer recess of the UK's parliament, for example. We selected the 
same three-week period to present a consistent sampling strategy. Instead of randomised sampling we collected all articles from the chosen periods, for two reasons. First, following the approach adopted by Heft et al's (2019: 14), this contextualised our analysis within an accurate understanding of publishing routines and output. Secondly, this enabled us to monitor significant events occurring within the sample periods, (such as the Manchester Arena bombing in May, 2017) as a control variable.

Table 1. Sample size and distribution

\begin{tabular}{|c|c|c|c|c|c|}
\hline Outlet & 2015 & 2016 & 2017 & 2018 & Total \\
\hline \multicolumn{6}{|l|}{ Left-wing } \\
\hline The Canary & 62 & 105 & 421 & 138 & 726 \\
\hline Another Angry Voice & 4 & 6 & 119 & 7 & 136 \\
\hline The Skwawkbox & - & 31 & 210 & 88 & 329 \\
\hline Evolve Politics & 1 & 22 & 56 & 23 & 102 \\
\hline Novara Media & 3 & 7 & 15 & 4 & 29 \\
\hline \multicolumn{6}{|l|}{ Right-wing } \\
\hline Westmonster & - & - & 242 & 147 & 389 \\
\hline Guido Fawkes & 130 & 136 & 410 & 173 & 849 \\
\hline Breitbart London & 135 & 135 & 263 & 93 & 626 \\
\hline Conservative Woman & 33 & 48 & 110 & 75 & 266 \\
\hline All Outlets & 368 & 490 & 1846 & 748 & 3452 \\
\hline
\end{tabular}

Westmonster was launched in 2017. The Skwawkbox did not publish content in October 2015.

The sample was selected on the basis of representing a cross section of right-wing and left-wing outlets reported to have the largest audience reach, principally via social media (Waterson, 2017). Unlike traditional mainstream outlets, the general typology of outlets we selected was not well understood prior to our analysis. Our criteria excluded sites such as HuffPost or BuzzFeed News because they are linked to corporate media and are not defined in opposition to mainstream media. Some of the organisations from which we draw our data are ostensibly very different (see Heft, et al, 2019 on “systemic variation”), which may be viewed as problematic when offering valid comparisons. Accordingly, we refer to our definition of AOPM and stress that inductively testing these comparisons through empirical research is a key aim of our study.

The content we collected was defined by its mixture of media genres, fluctuating style and edited alterations, which is often referred to as "liquidity" (Deuze, 2008). For example, many articles were solely consisted of video and audio content, particularly those produced by 
Novara Media, for example. Similar to Heft et al (2019: 18) when faced with a multimedia dataset, we removed these articles and in so doing acknowledge the limitations of analysing multimedia content - the most significant shortcoming here was the removal of 66 out of 95 non-text-based Novara Media publications. Owing to the variety of different website architectures, we also focused our data collection on the most comparable 'news' content sections offered by each outlet. The data was obtained by collecting publicly available URLs manually, or through the use of scraping software (see Appendix A).

\section{Interpretive Approach and Variables}

Our descriptive measures included the publication date, headline, and article author. Our interpretive measures for each article were based on five dependent variables, which were as follows:

i. Opinion- or fact-driven content. We interpreted whether an article was mainly driven by opinion or by factual information. In other words, we determined whether the article primarily relied on a series of opinions to form a narrative or argument or a descriptive account of events that was broadly considered 'news'. We sought to determine how the presentation of 'fact' and 'opinion' was balanced across each outlet on the basis that different forms of journalism function according to varying interpretations of the distinction between the two (Nygaard, 2019: 1150-1151). For example, while news journalism is often associated with 'objective' or 'neutral' reporting of 'facts', while journalists may also consider the sharing of opinion to be a crucial element of democratic deliberation (Deuze, 2005: 448).

ii. Topical coverage. We interpreted the primary, but not exclusive, topic of each article. We did so according to seventeen codes created during piloting (see appendix). We examined the range of topical coverage provided by each outlet on the basis that the range and distribution of topical coverage by a news organisation is a strong indicator of, and thus way of interpreting, its editorial values and agenda (Harcup and O’Neill, 2017: 1475).

iii. Policy coverage. Building on variable ii, we examined whether an article contained a discussion of at least one party or government policy, thus setting a low threshold.

iv. Party Political Focus. We determined, in addition to the article's topical focus, whether there was a focus on a particular political party. We included the Labour Party, The Conservative Party, The Liberal Democrats, UKIP, The Green Party, the SNP, Plaid Cymru, DUP, Sinn Fein and independent/other. 
v. Party Political Sentiment. Finally, we conducted a manual sentiment analysis on every instance of party-political focus identified in variable iv. We assessed whether the coverage was supportive, critical, or neutral (or 'unclear' if the sentiment was too complex). We designed this variable to examine the routine understanding of British alternative media as being “hyperpartisan” in their support or criticism of political parties (Rae, 2020).

All coding was performed manually by two human coders who completed three rounds of preliminary testing and training to establish confidence in the variables. They completed an intercoder reliability test on $10 \%$ of the total sample, itself based on randomly selecting $10 \%$ of the articles from each subsample of outlets. A score of $\mathrm{K}>.80$ was achieved across all variables (see Appendix B). We also performed an automated word frequency analysis, using NVivo, on the corpus of headline text.

\section{Findings and discussion: a typology of UK alternative online political media}

As mentioned, recent studies of alternative media have focussed on the fundamental question of how to define alternative media in national contexts. In line with the themes of this existing research, we present our findings as a typology of alternative online political media. We put forward four overlapping types: political cycle specialists; electoral hyperpartisans; cultural partisans; and vernacular macro-blogs. To help ground the presentation and discussion of the typology however, we begin by presenting the basic findings of our empirical analysis.

Table 2 shows the proportions of opinion and news articles. There is a clear divide between outlets that prioritise news or opinion, as well as evidence of shifts in orientation over time and during the election period. Breaking this down, in general, right-wing outlets produce more news content than left-wing outlets, with the exceptions of Conservative Woman and The Skwawkbox, respectively.

Table 2. Fact-driven (news) and opinion-driven (commentary) AOPM output

\begin{tabular}{|c|c|c|c|c|c|c|c|c|c|c|}
\hline \multirow[b]{2}{*}{ Outlet } & \multicolumn{5}{|c|}{ Fact-driven (news) articles \% (n) } & \multicolumn{5}{|c|}{$\begin{array}{c}\text { Opinion-driven (commentary) articles } \\
\%(n)\end{array}$} \\
\hline & 2015 & 2016 & $\begin{array}{c}201 \\
7\end{array}$ & 2018 & Total & 2015 & 2016 & 2017 & 2018 & Total \\
\hline Left-wing & & & & & & & & & & \\
\hline
\end{tabular}




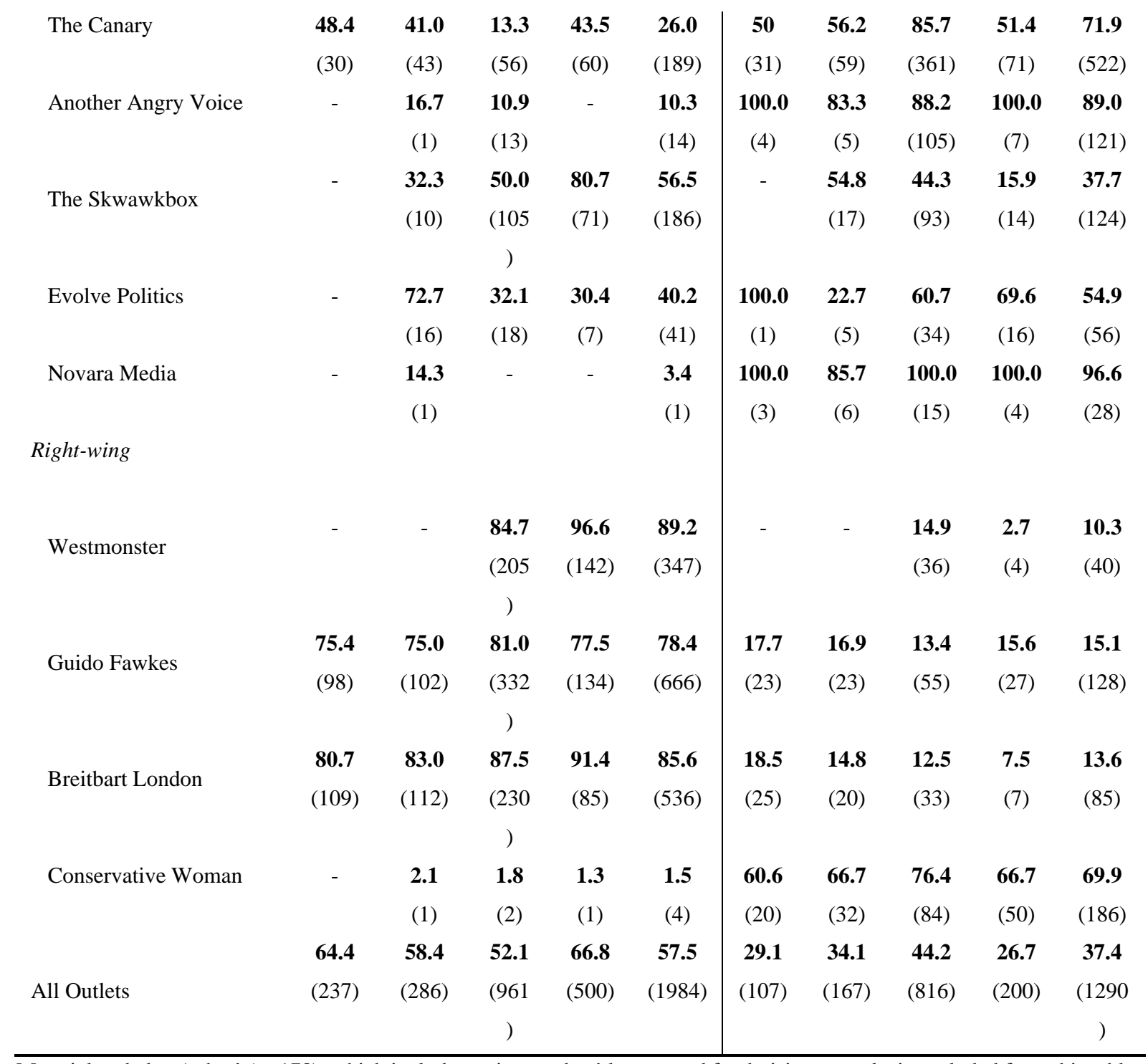

Material coded as 'other' ( $\mathrm{n}=178)$, which includes satire, readers’ letters, and fundraising appeals, is excluded from this table.

Table 3 shows the range of topical coverage. There were four main topics, with the top two - party political or media coverage - constituting 50.2\% of all content. EU affairs and social affairs (broadly covering issues such as LGBTQ+, religion, race, and discrimination) made up the third and fourth most common topics, respectively (see appendix for other topics). The most party-centric outlets in their coverage were The Canary, Guido Fawkes and The Skwawkbox. The Canary, Guido Fawkes and Conservative Woman were the leading providers of stories about the media, with Guido Fawkes ("Media Guido") and Conservative Woman (“BBC Watch”) having designated media sections. Westmonster and Breitbart London prioritised EU affairs, while left-wing outlets consistently avoided it as a topic. 
Table 3. Primary topic of coverage within AOPM content

\begin{tabular}{|c|c|c|c|c|c|}
\hline $\begin{array}{l}\text { Outlet } \\
\text { (2017 election) }\end{array}$ & $\begin{array}{l}\text { Party } \\
\text { Political } \\
\% \text { (n) }\end{array}$ & $\begin{array}{l}\text { Media } \\
\%(n)\end{array}$ & $\begin{array}{l}\text { EU Affairs } \\
\%(n)\end{array}$ & $\begin{array}{l}\text { Social Affairs } \\
\%(n)\end{array}$ & $\begin{array}{l}\text { All other } \\
\%(n)\end{array}$ \\
\hline \multicolumn{6}{|l|}{ Left-wing } \\
\hline The Canary & $40.9(297)$ & $20.9(152)$ & $2.1(15)$ & $7.3(53)$ & 28.8 (209) \\
\hline (2017) & $54.6(230)$ & 23.5 (99) & $1.0(4)$ & $3.8(16)$ & $17.1(72)$ \\
\hline Another Angry Voice & $45.6(62)$ & $8.1(11)$ & $5.1(7)$ & $6.6(9)$ & $34.6(47)$ \\
\hline (2017) & $48.7(58)$ & $7.6(9)$ & $5.0(6)$ & $6.7(8)$ & 31.9 (38) \\
\hline The Skwawkbox & 61.7 (203) & $12.8(42)$ & $1.2(4)$ & $3.3(11)$ & 21.0 (69) \\
\hline (2017) & $61.9(130)$ & $11.9(25)$ & - & - & $26.2(55)$ \\
\hline Evolve Politics & $\mathbf{5 1 . 0}(52)$ & $15.7(16)$ & $2.0(2)$ & $3.9(4)$ & $27.5(28)$ \\
\hline (2017) & $67.9(38)$ & $16.1(9)$ & - & $1.8(1)$ & $14.3(8)$ \\
\hline Novara Media & $31.0(9)$ & $3.4(1)$ & $6.9(2)$ & $6.9(2)$ & $51.7(15)$ \\
\hline (2017) & $46.7(7)$ & - & $6.7(1)$ & - & $46.7(7)$ \\
\hline \multicolumn{6}{|l|}{ Right-wing } \\
\hline Westmonster & $24.4(95)$ & $3.3(13)$ & 35.0 (136) & $14.4(56)$ & 22.9 (89) \\
\hline (2017) & $27.3(66)$ & $5.0(12)$ & $22.7(55)$ & $19.8(48)$ & $25.2(61)$ \\
\hline Guido Fawkes & $45.0(382)$ & 12.8 (109) & $9.1(77)$ & $3.7(31)$ & $29.4(250)$ \\
\hline (2017) & $61.7(253)$ & $13.2(54)$ & $2.2(9)$ & $3.9(16)$ & $19.0(78)$ \\
\hline Breitbart London & $18.7(117)$ & $7.0(44)$ & $23.6(148)$ & $11.5(72)$ & 39.1 (245) \\
\hline (2017) & $22.1(58)$ & $6.8(18)$ & $16.2(43)$ & $11.0(29)$ & 43.7 (115) \\
\hline Conservative Woman & $26.3(70)$ & $21.4(57)$ & $11.3(30)$ & 14.7 (39) & $26.3(70)$ \\
\hline (2017) & $41.8(46)$ & $23.6(26)$ & $6.4(7)$ & $10.9(12)$ & $17.3(19)$ \\
\hline All Outlets & $37.3(1287)$ & $12.9(445)$ & $12.2(421)$ & $\mathbf{8 . 0}(277)$ & $29.6(1022)$ \\
\hline
\end{tabular}

Isolated 2017 election sample $\mathrm{N}=1846$. 'All other' includes coverage of: parliament; government; economics; defence; immigration; foreign affairs; education; NHS and social care; environment; infrastructure; science and technology; and arts, culture and sport.

Figure 1 shows the balance of coverage given to all the political parties by each outlet (variable iv). Consistent with establishing that party political coverage was the central topic for most outlets, $64.8 \%$ of articles also focused on a particular party. Of these, $34.6 \%$ and 54.4\% focused on the Labour Party and The Conservative Party, respectively, revealing an overwhelming two-party focus. The Skwawkbox provided the biggest portion of Labour Party coverage (45.3\%), while The Canary (54.5\%) and Another Angry Voice (61.8\%) focused the most on The Conservative Party. Only UKIP, which received 10.0\% of Breitbart London's coverage, significantly featured elsewhere. The Liberal Democrats were overwhelmingly ignored, receiving - at most - only 2.0\% of Guido Fawkes’ coverage. 
Figure 1. Percentage of all content which focuses on a particular political party, per outlet.

None $\square$ Labour

Conservative

Liberal democrat

Green SNP

Plaid Cymru

DUP

Independent/other

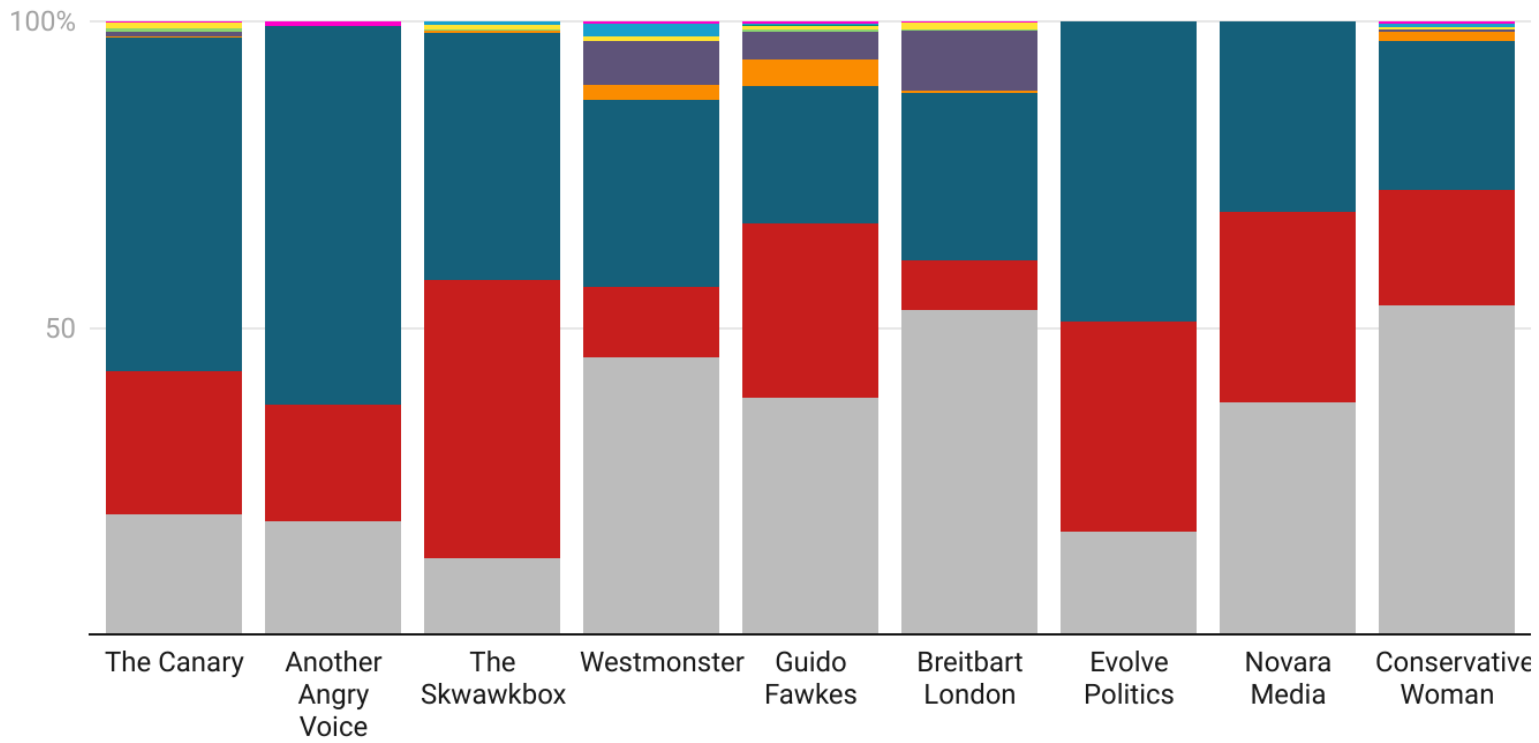

N=3452 articles. Subsample sizes vary, see table 1.

Table 4 shows the balance of critical and supportive sentiment given to the two main political parties (variable v). Within party-focussed coverage, Another Angry Voice was the most critical (62.5\%), followed by The Canary (56.9\%). Evolve Politics (52.0\%). Breitbart London (17.0\%) and Westmonster (25.7\%) were the least critical. The percentage of neutral content was notably even lower, with only Guido Fawkes (17.1\%) and Breitbart London (25.1\%) offering it to any degree. The findings can be interpreted as evidence of partisanship among all of the left-wing outlets, including (based on limited evidence) Novara Media. For example, $100.0 \%$ of the supportive coverage provided by The Skwawkbox went to the Labour Party and 95.6\% of The Canary's critical coverage was aimed at the Conservative Party. Rightwing outlets, however, present a more complex picture. Breitbart London are more critical of the Conservatives than Labour, while Westmonster and Conservative Woman were equally critical of the two. 
Table 4. Percentage of party_-focused content that is critical or supportive towards the Conservative Party and Labour Party

\begin{tabular}{|c|c|c|}
\hline $\begin{array}{l}\text { Outlet } \\
\text { (Sentiment) }\end{array}$ & $\begin{array}{l}\text { Labour } \\
\%(n)\end{array}$ & $\begin{array}{l}\text { Conservative } \\
\% \text { (n) }\end{array}$ \\
\hline \multicolumn{3}{|l|}{ Left-wing } \\
\hline The Canary (Crit) & $2.4(10)$ & 95.6 (395) \\
\hline The Canary (Sup) & $94.9(148)$ & $0.6(1)$ \\
\hline Another Angry Voice (Crit) & $1.2(1)$ & $98.8(84)$ \\
\hline Another Angry Voice (Sup) & $95.8(23)$ & - \\
\hline The Skwawkbox (Crit) & $2.8(4)$ & 93.0 (133) \\
\hline The Skwawkbox (Sup) & $100.0(88)$ & - \\
\hline Evolve Politics (Crit) & $5.7(3)$ & $94.3(50)$ \\
\hline Evolve Politics (Sup) & $100.0(26)$ & - \\
\hline Novara Media (Crit) & - & $100.0(9)$ \\
\hline Novara Media (Sup) & $100.0(5)$ & - \\
\hline \multicolumn{3}{|l|}{ Right-wing } \\
\hline Westmonster (Crit) & $41.0(41)$ & $46.0(46)$ \\
\hline Westmonster (Sup) & $2.5(1)$ & $30.0(12)$ \\
\hline Guido Fawkes (Crit) & $59.9(194)$ & $25.0(81)$ \\
\hline Guido Fawkes (Sup) & $19.4(6)$ & $74.2(23)$ \\
\hline Breitbart London (Crit) & $33.0(35)$ & $59.4(63)$ \\
\hline Breitbart London (Sup) & - & $30.0(6)$ \\
\hline Conservative Woman (Crit) & $44.9(48)$ & $48.6(52)$ \\
\hline Conservative Woman (Sup) & - & $\mathbf{9 0 . 0}(9)$ \\
\hline
\end{tabular}

$\mathrm{N}=1597$. Neutral and unclear content is excluded from the table results.

Despite some proposing an homogenous view of newer alternative media, our analysis reveals that there are various types of AOPM active in the UK. We thus build on the work of Schwarzenegger (2021) and Heft et al (2019; 2020), who advocate more heterogeneous understandings of alternative media. Building on the related conceptual arguments of Dueze and Holt et al's (2019) relational model, the typology that follows discusses and outlines this complexity. It should be stressed that outlets may exhibit properties that overlap across the typology. Within a hybrid media system, this is to be expected, as genres and media logics are fluid. In fact, we argue, AOPM are an extension and intensification of the indeterminacy that typifies a hybrid media system. 


\section{Political Cycle Specialists}

The first type of AOPM outlet we define is political cycle specialists. We identify these as outlets which understand and act within a "political information cycle”, in which they aim to publish specialist or niche news content that can influence the media agenda and/or contest framings within "fluid opportunity structures”, as opposed to the fixed routines of traditional news cycles (Chadwick, 2017: 72-75). As such, these outlets do not attempt to provide a broad range of coverage, but rather focus on specific topics or issues to asymmetrically influence the political agenda. In terms of their coverage, these outlets are unlike many established news outlets in the UK that have dedicated news divisions. Moreover, they are placed in relation to the broad agenda-setting power of larger organisations such as the BBC or The Times.

Among the outlets in our study, Guido Fawkes and The Skwawkbox exemplify this definition. Both outlets produce large volumes of news content focused on specific topics. The Skwawkbox, for example, focuses on providing granular coverage of the Labour Party, while Guido Fawkes likewise focused heavily on party politics and was also the only site to provide consistent parliamentary coverage (i.e. legislative processes). Importantly, there is a clear adherence to the values of immediacy and exclusivity in their articles, with regular articles that are often only a few hundred words long, that focuses on process or breaking stories rather than policy analysis, as table 5 shows.

Table 5. AOPM content containing policy coverage

\begin{tabular}{|c|c|c|c|c|c|}
\hline Outlet & $2015 \%$ (n) & $2016 \%$ (n) & $2017 \%$ (n) & $2018 \%$ (n) & Total \% (n) \\
\hline \multicolumn{6}{|l|}{ Left-wing } \\
\hline The Canary & $\mathbf{5 0 . 0}(31)$ & $17.1(18)$ & $27.6(116)$ & $55.1(76)$ & $33.2(241)$ \\
\hline Another Angry Voice & 100.0 & $\mathbf{5 0 . 0}(3)$ & $28.6(34)$ & $42.9(3)$ & $32.4(44)$ \\
\hline The Skwawkbox & - & $16.1(5)$ & $42.4(89)$ & $3.4(3)$ & $29.5(97)$ \\
\hline Evolve Politics & - & $54.5(12)$ & $44.6(25)$ & $39.1(9)$ & $45.1(46)$ \\
\hline Novara Media & $33.3(1)$ & $42.9(3)$ & $\mathbf{6 0 . 0}(9)$ & $\mathbf{5 0 . 0}(2)$ & $51.7(15)$ \\
\hline \multicolumn{6}{|l|}{ Right-wing } \\
\hline Westmonster & - & - & $23.6(57)$ & $49.7(73)$ & 33.4 (130) \\
\hline Guido Fawkes & $11.5(15)$ & $16.9(23)$ & 9.0 (37) & $13.3(23)$ & $11.5(98)$ \\
\hline Breitbart London & $56.3(76)$ & $26.7(36)$ & $6.8(18)$ & $54.8(51)$ & $28.9(181)$ \\
\hline Conservative Woman & $24.2(8)$ & $47.9(23)$ & $40.0(44)$ & $29.3(22)$ & $36.5(97)$ \\
\hline
\end{tabular}

Table shows only positive cases within samples presented in Table 1.

This content also often exhibits a blurring of news and comment. For example, Guido Fawkes inserts red text into all its content to signify an explicit editorial viewpoint, while The 
Skwawkbox provides commentary in a separate on-screen box from the main article text. Thus, the specific informative angles are also enmeshed with the editorial position of the outlets, with The Skwawkbox supportive of Labour and Guido Fawkes more generally critical of political parties, but slightly favouring The Conservatives.

\section{(Left-wing) Electoral Hyperpartisans}

The second type of AOPM we propose is electoral hyperpartisans. We define these as outlets which produce large amounts of opinion (and news) coverage in support of the electoral aims of a particular political party, with which they ideologically align. As such, they fit the view that newer alternative media aim to provide political information intended to "directly influence electoral politics” (Rauch, 2016: 764). The outlet’s role as an electoral hyperpartisan is dynamic. For example, it can intensify during elections; table 2 shows how the spike in election output was driven by opinion content by several sites. It can also be contingent on the leadership and ideological direction of a party, which may itself change. Relationally, electoral hyperpartisans have similar features to the UK press in terms of high levels of criticism, although unlike the press are far more supportive of a particular party (see Deacon, et al 2017).

The left-wing outlets The Canary and Evolve Politics best define this type of AOPM, as does The Skwawkbox, though it is not an inherently left-wing categorisation, we argue. Unlike political cycle specialists, The Canary and Evolve Politics produce higher volumes of commentary and focus on a broader range of topics. The key finding is, as table 4 shows, that these outlets consistently provided party political coverage that was heavily critical and supportive of the Conservative and Labour party, respectively, to a degree that we could consider to be "hyperpartisan" (Rae, 2020). With the press also being more critical of the Labour Party, these left-wing electoral hyperpartisans indicate a dialectical reaction within the British media system. Table 6 reinforces this argument, with specific evidence from the 2017 general election.

Table 6. Percentage of critical and supportive sentiment towards the Conservative Party and Labour Party during the 2017 general election.

\begin{tabular}{lll} 
Outlet & Labour (2017) & Conservative (2017) \% (n) \\
(Sentiment) & $\%(n)$ & \\
\hline
\end{tabular}




\begin{tabular}{|c|c|c|}
\hline The Canary (Crit) & $0.4(1)$ & $96.7(236)$ \\
\hline The Canary (Sup) & 97.7 (126) & $0.8(1)$ \\
\hline Another Angry Voice (Crit) & $1.4(1)$ & $98.6(72)$ \\
\hline Another Angry Voice (Sup) & $95.8(23)$ & - \\
\hline The Skwawkbox (Crit) & $0.8(1)$ & $98.4(124)$ \\
\hline The Skwawkbox (Sup) & $\mathbf{1 0 0 . 0}(62)$ & - \\
\hline Evolve Politics (Crit) & $3.8(1)$ & $96.2(25)$ \\
\hline Evolve Politics (Sup) & $100.0(20)$ & - \\
\hline Novara Media (Crit) & - & $100.0(7)$ \\
\hline Novara Media (Sup) & $100.0(2)$ & - \\
\hline \multicolumn{3}{|l|}{ Right-wing } \\
\hline Westmonster (Crit) & $47.3(35)$ & $40.5(30)$ \\
\hline Westmonster (Sup) & - & $11.5(3)$ \\
\hline Guido Fawkes (Crit) & $59.8(116)$ & $22.2(43)$ \\
\hline Guido Fawkes (Sup) & $6.3(1)$ & $87.5(14)$ \\
\hline Breitbart London (Crit) & $53.6(15)$ & $39.3(11)$ \\
\hline Breitbart London (Sup) & - & $37.5(3)$ \\
\hline Conservative Woman (Crit) & $62.5(35)$ & $28.6(16)$ \\
\hline Conservative Woman (Sup) & - & $100.0(6)$ \\
\hline
\end{tabular}

$\mathrm{N}=1597$. Isolated 2017 election sample $\mathrm{N}=1030$

These results should be seen in conjunction with those in table 8 (below), which shows how The Canary and Evolve Politics increased their commentary output during the 2017 general election, emphasizing their role as electoral hyperpartisans. Table 7 also suggests that electoral hyperpartisans associate their roles with party leadership, namely Jeremy Corbyn (Labour) and Theresa May (Conservative). In this aspect, in their roles as electoral hyperpartisans, The Canary and Evolve Politics appear highly contingent on party leadership, and therefore can be reasonably described as having a febrile nature.

Table 7. Most common words within AOPM headlines

\begin{tabular}{lccccc}
\hline Outlet & 1. & 2. & 3. & & \\
\hline Left-wing & & & & \\
The Canary & Video & May & Theresa & Tory & Corbyn \\
Another Angry Voice & Tory & Theresa & May & Right & Corbyn \\
The Skwawkbox & \#ge17 & May & Tories & Labour & Corbyn \\
Evolve Politics & Tory & Corbyn & Just & Labour & May \\
Novara Media & Labour & Ways & Hold & Reasons & Election \\
Right-wing & & & & &
\end{tabular}




\begin{tabular}{lccccc}
\hline Westmonster & Brexit & May & Tory & Deal & Labour \\
Guido Fawkes & Corbyn & May & Labour & Tory & Campaign \\
Breitbart London & Brexit & Britain & Attack & May & Terror \\
Conservative Woman & BBC & Comment & Reader & May & Lefty \\
\hline
\end{tabular}

Results derived from word frequency analysis function in NVivo. Results include similar words, i.e. 'Tory', 'Tories'.

Analysis performed on full sample of each AOPM outlet

\section{(Right-wing) Cultural Partisans}

Third, we suggest the term cultural partisans. We define these as outlets that broadly follow the so-called Breitbart Doctrine that "politics is downstream from culture". Their content is committed to supporting particular sides of a cultural issue, such as Brexit or immigration (see Nygaard, 2019, on “Immigration-Critical Alternative Media”), often from a populist perspective. Therefore, unlike electoral hyperpartisans, this support is not necessarily aligned to a political party. Moreover, these outlets tend to rely on (highly selective) news content, where specific coverage is valued in pursuit of an ideological agenda (see Harcup \& O’Neill, 2017: 1482). In terms of their agenda, issue partisans are not unlike the tabloid press. However, their range of overall coverage is much narrower. As such, they may complement or feed from existing elements of the media system. Thus, understood relationally, they appear as offshoots of the tabloid media that often campaign over particular issues.

We identify Breitbart London and Westmonster as meeting our definition of this type of AOPM, with Conservative Woman a more commentary-based caveat. Unlike electoral hyperpartisans, Table 8 shows that these two outlets focused mainly on providing news coverage of EU affairs and social affairs. This is also reflected in Table 7, which shows that 'Brexit' was the most common headline word for both outlets. Moreover, $80 \%$ of all immigration coverage came from Westmonster, Breitbart London, and Conservative Woman. However, similar to electoral hyperpartisans, cultural partisans also focus on a broader range of topics, but unlike electoral hyperpartisans (and more akin to political cycle specialists) they produce higher volumes of news content. 
Table 8. Primary topic of coverage within AOPM content, isolated within fact-driven (news) and opinion-driven (commentary) content

\begin{tabular}{|c|c|c|c|c|c|}
\hline \multirow{3}{*}{ Outlet } & Party & Media & EU Affairs & Social Affairs & All other \\
\hline & Political & $\%(n)$ & $\%(n)$ & $\%(n)$ & $\%(n)$ \\
\hline & $\%(n)$ & & & & \\
\hline \multicolumn{6}{|l|}{ Left-wing } \\
\hline The Canary $(\mathrm{N})$ & 33.3 (63) & $12.2(23)$ & $3.7(7)$ & $8.5(16)$ & $42.3(80)$ \\
\hline The Canary (C) & $44.4(232)$ & $23.9(125)$ & $1.5(8)$ & $6.5(34)$ & 23.6 (123) \\
\hline Another Angry Voice (N) & $64.3(9)$ & $7.1(1)$ & - & - & 28.6 (4) \\
\hline Another Angry Voice (C) & $43.8(53)$ & $8.3(10)$ & - & $7.4(9)$ & $34.7(42)$ \\
\hline The Skwawkbox (N) & $63.4(118)$ & $11.3(21)$ & $1.6(3)$ & $4.8(9)$ & $18.8(35)$ \\
\hline The Skwawkbox (C) & $62.1(77)$ & $13.7(17)$ & $0.8(1)$ & $1.6(2)$ & $21.8(27)$ \\
\hline Evolve Politics (N) & $48.8(20)$ & $9.8(4)$ & - & $4.9(2)$ & 36.6 (15) \\
\hline Evolve Politics (C) & $55.4(31)$ & $19.6(11)$ & $3.6(2)$ & $3.6(2)$ & $17.9(10)$ \\
\hline Novara Media (N) & - & - & - & - & $100.0(1)$ \\
\hline Novara Media (C) & $32.1(9)$ & $3.6(1)$ & $7.1(2)$ & $7.1(2)$ & $50.0(14)$ \\
\hline \multicolumn{6}{|l|}{ Right-wing } \\
\hline Westmonster (N) & $22.8(79)$ & $2.6(9)$ & 36.9 (128) & $14.4(50)$ & $23.3(81)$ \\
\hline Westmonster (C) & $37.5(15)$ & $10.0(4)$ & $20.0(8)$ & $15.0(6)$ & $17.5(7)$ \\
\hline Guido Fawkes (N) & $48.2(321)$ & $13.2(88)$ & $9.3(62)$ & $4.1(27)$ & $25.2(168)$ \\
\hline Guido Fawkes (C) & $40.6(52)$ & $15.6(20)$ & $10.9(14)$ & $2.3(3)$ & 30.5 (39) \\
\hline Breitbart London (N) & $17.5(94)$ & $5.0(27)$ & $24.3(130)$ & $11.8(63)$ & $41.4(222)$ \\
\hline Breitbart London (C) & $22.4(19)$ & $20.0(17)$ & $21.2(18)$ & $10.6(9)$ & $25.9(22)$ \\
\hline Conservative Woman (N) & $25.0(1)$ & $25.0(1)$ & - & $\mathbf{5 0 . 0}(2)$ & - \\
\hline Conservative Woman (C) & $25.8(48)$ & $22.0(41)$ & $10.2(19)$ & $14.5(27)$ & $27.4(51)$ \\
\hline
\end{tabular}

$\mathrm{N}=$ news. $\mathrm{C}=$ commentary. See table 5 for description of 'all other'. Content which was not FD or OD was excluded, see table 3.

Unlike the electoral hyperpartisans, these right-wing outlets were generally critical of both main parties. We found that Westmonster and Breitbart London respectively gave 60.0\% and $70.0 \%$ of their supportive coverage to UKIP, albeit in real terms, this represented a small number of articles. Moreover, the intense focus on particular cultural issues demonstrates some stability - and even rigidity- within their news agendas. This likely stems from the fact that their agenda-driven editorial positions are closely associated with their original raison d'etre. As such, if these issues become less compelling or important, the long term longevity of these outlets might be a pertinent factor (for example, Westmonster ceased to exist in 2020). 


\section{Vernacular Macro-blogs}

Our final category emerges from our examination of content produced by Another Angry Voice. In this case, our analysis identifies significant commentary, embracing the features congruent with an electoral hyperpartisan. Stylistically, however, it is unlike the electoral hyperpartisans, and features a broader range of "all other" content. Consequently, we suggest the term vernacular macro-blogs. These are highly stylised blogs, with a larger than average following and wider social media presence beyond that of the core blog. The blogs have a clear political orientation but lack editorial functions, meaning that much of their content might be considered "idiosyncratic". Another Angry Voice, for example, has over 300,000 Facebook followers and is based around the personality of Yorkshireman Thomas G. Clarke. To a lesser extent, The Skwawkbox and Guido Fawkes (particularly in earlier years) would fit this typology; Guido Fawkes describes itself as a "news site with a blog heritage” (Guido Fawkes, 2020).

\section{Conclusions}

This study has carried out a systematic content analysis of alternative media content in the UK $(\mathrm{N}=3452)$ and identifies a diversity within this content. In conjunction with the other studies which have sought to gain fundamental understandings of alternative media, we have provided a typology of alternative media in the UK.

To some degree, all of the outlets in our study exhibit features that overlap within this typology. For example, to some degree, The Skwawkbox could be considered as a political cycle specialist, electoral hyperpartisan, and a vernacular macro-blog. Moreover, there are many other AOPM outlets that we have not examined that may fit this typology or might lead to amendments to it, such as Byline Times for example. Within our analysis, the variation in subsample distributions limits the strength and availability of certain inferences made towards outlets whose content is relatively underrepresented in the data, and we fully acknowledge this. Our findings for example, are insufficient to categorise Novara Media, although we argue that it clearly represents a particular type of content, especially with regards to their multimedia output. Also important to note is that our longitudinal perspective may offer a recent historical analysis, but that the editorial focuses and thus content of these outlets already have changed in response to recent political events, such the 2019 general election, or Brexit.

Not only do our findings and analysis offer only some insight into AOPM, they also raise a number of considerations for further study and debate. For example, how do these types of outlet fit within the broader media system? Our theoretical perspective and discussion touches upon this, such as how issue partisans resemble the tabloid press or political cycle 
specialists compete with larger news operations. But more generally, how does the presence of electoral hyperpartisans or cultural partisans, for example, change the exchange of information within the media system? To what extent do they challenge the normative expectations contained within “journalism's traditional notions of objectivity”, as Rae (2020: 2) argues they do?

As the basis for further research, we propose the further identification and analysis of similarities and differences in content, in relation to the mainstream media, to help understand these key questions. Moreover, qualitative research would, we feel, help to further understand how, as part of their 'alternativeness' to mainstream media, alternative media outlets “discursively construct” (see Hanitzsch and Vos 2017) themselves within the media system, and, more generally, gain an inside perspective of how these outlets operate.

\section{References}

Atton, C. (2002). Alternative Media. Thousand Oaks: Sage Publications.

Chakelian, A. (2017). “Luxury communism now!” The rise of the pro-Corbyn media. New Statesman. https://www.newstatesman.com/politics/media/2017/09/luxury-communism-now-rise-pro-corbyn$\underline{\text { media }}$

Conte, M. L. (2016). How A Pro-Corbyn Viral Website With A Pay-Per-Click Business Model Is Taking Over Social Media. BuzzFeed News. https://www.buzzfeed.com/marieleconte/the-rise-of-the-canary

Couldry, N., \& Curran, J. (2003). Contesting Media Power: Alternative Media in a Networked World.

Deuze, M. (2005). What is journalism?: Professional identity and ideology of journalists reconsidered. Journalism, 6(4), 442-464.

Deuze, M. (2008) The changing context of news work: Liquid journalism and monitorial citizenship. International Journal of Communication, 2(5), 848-865.

Deuze, M. (2019). What Journalism Is (Not). Social Media + Society, 5(3), 1-4.

Dodson, S. (2018). How new media recycles the mainstream press. The Conversation. http://theconversation.com/how-new-media-recycles-the-mainstream-press-105459

Dolan, A. (2015). Novara: New media for a different politics. Red Pepper. https://www.redpepper.org.uk/novara-new-media-for-a-different-politics/

Downing, J. D. H., Ford, T. V., Gil, G., \& Stein, L. (2001). Radical Media: Rebellious Communication and Social Movements. Thousand Oaks:SAGE Publications.

Figenschou, T. U., \& Ihlebæk, K. A. (2019). Challenging Journalistic Authority. Journalism Studies, 20(9), 1221-1237.

Fletcher, R., Newman, N., \& Schulz, A. (2020). Digital News Project 2020: A Mile Wide, an Inch Deep: Online News and Media Use in the 2019 UK General Election. http://www.digitalnewsreport.org

Gibbs, P. L., \& Hamilton, J. (2001). Alternative Media in Media History. Media History, 7(2), 117-118. 
Guido Fawkes. (2020). About. Guido Fawkes. https://order-order.com/about/

Hanitzsch, T., \& Vos, T. P. (2017). Journalistic Roles and the Struggle Over Institutional Identity: The Discursive Constitution of Journalism. Communication Theory, 27(2), 115-135.

Haller, A., \& Holt, K. (2019). Paradoxical populism: How PEGIDA relates to mainstream and alternative media. Information, Communication \& Society, 22(12), 1665-1680.

Hamilton, J., \& Atton, C. (2001). Theorizing Anglo-American Alternative Media: Toward a contextual history and analysis of US and UK scholarship. Media History, 7(2), 119-135.

Harcup, T. (2005). “I'm Doing this to Change the World”: Journalism in alternative and mainstream media. Journalism Studies, 6(3), 361-374.

Harcup, T., \& O’Neill, D. (2017). What is News? Journalism Studies, 18(12), 1470-1488.

Heft, A., Mayerhöffer, E., Reinhardt, S., \& Knüpfer, C. (2019). Beyond Breitbart: Comparing Right-Wing Digital News Infrastructures in Six Western Democracies. Policy \& Internet.

Heft, A., Knüpfer, C., Reinhardt, S., \& Mayerhöffer, E. (2020). Toward a Transnational Information Ecology on the Right? Hyperlink Networking among Right-Wing Digital News Sites in Europe and the United States. The International Journal of Press/Politics, Online First, 1-21.

Holt, K. (2018). Alternative Media and the Notion of Anti-Systemness: Towards an Analytical Framework. Media and Communication, 6(4), 49-57.

Holt, K. (2019). Right-Wing Alternative Media. Abingdon: Routledge

Holt, K., Figenschou, T. U., \& Frischlich, L. (2019). Key Dimensions of Alternative News Media. Digital Journalism, Early Access, 1-10.

Jackson, J. (2017, January 19). Arron Banks launches Breitbart-style site Westmonster. The Guardian. https://www.theguardian.com/media/2017/jan/19/arron-banks-launches-breitbart-style-sitewestmonster

Kalogeropoulos, A., \& Newman, N. (2018). Who Uses Alternative and Partisan Brands? https://www.digitalnewsreport.org/survey/2018/who-uses-alternative-and-partisan-brands/

Nielsen, R. K., \& Ganter, S. A. (2018). Dealing with digital intermediaries: A case study of the relations between publishers and platforms. New Media \& Society, 20(4), 1600-1617.

Newman, N., Fletcher, R., Kalogeropoulos, A., \& Nielsen, R. K. (2019). Reuters Institute Digital News Report 2019. http://www.digitalnewsreport.org/survey/2019/overview-key-findings-2019/

Nicholls, T., Shabbir, N., Graves, L., \& Nielsen, R. K. (2018). Coming of Age: Developments in Digital-Born News Media in Europe. https://www.digitalnewsreport.org/publications/2018/coming-agedevelopments-digital-born-news-media-europe/

Noppari, E., Hiltunen, I., \& Ahva, L. (2019). User profiles for populist counter-media websites in Finland. Journal of Alternative and Community Media, 4(1), 23-37.

Mayhew, F. (2017, October 26). Staines says scoops have put Guido Fawkes back above The Canary but praises rival's 'extraordinary success'. Press Gazette. https://www.pressgazette.co.uk/staines-says-scoopshave-put-guido-fawkes-back-above-the-canary-but-praises-rivals-extraordinary-success/

Mayhew, F. (2016, October 20). The Canary: From $£ 500$ start-up to top-100 UK news website in the space of a year. Press Gazette. https://www.pressgazette.co.uk/the-canary-from-500-start-up-to-top-100-uk-newswebsite-in-the-space-of-a-year/ 
Nygaard, S. (2019). The Appearance of Objectivity: How Immigration-Critical Alternative Media Report the News. Journalism Practice, 13(10), 1147-1163.

Nygaard, S. (2020). Boundary Work: Intermedia Agenda-Setting Between Right-Wing Alternative Media and Professional Journalism. Journalism Studies, Online First, 1-17.

Peacock, C., Hoewe, J., Panek, E., \& Willis, G. P. (2020). Hyperpartisan News Use: Relationships with Partisanship and Cognitive and Affective Involvement. Mass Communication and Society, Online First, 1-23.

Rae, M. (2020). Hyperpartisan news: Rethinking the media for populist politics. New Media \& Society, Online First.

Rauch, J. (2016). Are There Still Alternatives? Relationships Between Alternative Media and Mainstream Media in a Converged Environment. Sociology Compass, 10(9), 756-767.

Riebling, J. R., \& Wense, I. von der. (2019). Framing the mass media: Exploring ‘fake news’ as a frame embedded in political discourse. Journal of Alternative and Community Media, 4(1), 57-76.

Robertson, C. T., \& Mourão, R. R. (2020). Faking Alternative Journalism? An Analysis of Self-Presentations of “Fake News” Sites. Digital Journalism, 0(0), 1-19. https://doi.org/10.1080/21670811.2020.1743193

Schulze, H. (2020). Who Uses Right-Wing Alternative Online Media? An Exploration of Audience Characteristics. Politics and Governance, 8(3), 6-18.

Schwarzenegger, C. (2021). Communities of Darkness? Users and Uses of Anti-System Alternative Media between Audience and Community. Media and Communication, 9(1), 99-109. https://doi.org/10.17645/mac.v9i1.3418

Spence, A. (2016, August 18). Jeremy Corbyn and the disruptive Canary. POLITICO. https://www.politico.eu/blogs/on-media/2016/08/jeremy-corbyn-and-the-disruptive-canary-uk-politicslabour-leader/

Turvill, W. (2015). Guido Fawkes ten years on: 'I didn’t go into Westminster to make friends, and I've achieved that'. Press Gazette. https://www.pressgazette.co.uk/guido-fawkes-ten-years-i-didnt-go-westminster$\underline{\text { make-friends-and-ive-achieved/ }}$

Waterson, J. (2017). How A Small Group Of Pro-Corbyn Websites Built Enormous Audiences On Facebook. BuzzFeed News. https://www.buzzfeed.com/jimwaterson/the-rise-of-the-alt-left

Woolf, N. (2019). The rise and fall of Breitbart. New Statesman. https://www.newstatesman.com/world/northamerica/2019/07/rise-and-fall-breitbart

Appendix A. URL collection hyperlink roots

\begin{tabular}{lc} 
Variable & Root URL \\
\hline The Canary & https://www.thecanary.co/uk \\
Another Angry Voice & https://anotherangryvoice.blogspot.com \\
The Skwawkbox & https://skwawkbox.org \\
Westmonster & https://www.westmonster.com \\
Guido Fawkes & https://order-order.com
\end{tabular}


Breitbart London

Evolve Politics

Novara Media

Conservative Woman https://www.breitbart.com/europe

https://evolvepolitics.com

https://novaramedia.com

https://conservativewoman.co.uk

Appendix B. Intercoder reliability score

\begin{tabular}{lcc}
\hline Variable & Level of agreement \% & Cohen’s Kappa \% \\
\hline i. Fact/opinion & 89.3 & 0.81 \\
ii. Topical Coverage & 83.0 & 0.80 \\
iii. Policy Coverage & 90.9 & 0.81 \\
iv. Party Focus & 93.4 & 0.90 \\
v. Party Sentiment & 86.6 & 0.81 \\
\hline
\end{tabular}

